resection was recommended to prevent local tumor recurrence, even if this operation impaired the patient's quality of life (bypass, valve replacement, and ventricular septal defect patch closure) ${ }^{2}$ Cases of cardiac transplantation to treat these fibromas have also been reported. ${ }^{4}$ However, subtotal resection seems to be the best therapeutic option when the size or location of the tumor makes total resection impossible. The risk of tumor regrowth seems to be relatively low. Several colleagues have described the absence of tumor progression at long-term follow-up, even if the number of cases reported is low. Finally, transplantation does not seem to be an acceptable option, even with voluminous fibromas; subtotal resection should be the treatment of choice. ${ }^{5}$

Even if it is widely accepted that fibromas should be totally resected because of their recurrence risk, subtotal surgical intervention might be an acceptable option when the volume or location of the tumor makes total resection a high-risk procedure.

\section{References}

1. Burke AP, Rosado-de-Christenson M, Templeton PA, Virmani R. Cardiac fibroma: clinicopathologic correlates and surgical treatment. $J$ Thorac Cardiovasc Surg. 1994; 108:862-70.

2. Alter P, Grimm W, Rominger MB, Ritter M, Klose KJ, Moosdorf R, et al. Right ventricular cardiac myxoma. Diagnostic usefulness of cardiac magnetic resonance imaging. Herz. 2005;30:663-7.

3. Yamaguchi M, Hosokawa Y, Ohashi H, Imai M, Oshima Y, Minamiji K. Cardiac fibroma. Long-term fate after excision. J Thorac Cardiovasc Surg. 1992;103:140-5.

4. Valente M, Cocco P, Thiene G, Casula R, Poletti A, Milanesi O, et al. Cardiac fibroma and heart transplantation. J Thorac Cardiovasc Surg. 1993;106:1208-12.

5. Cho JM, Danielson GK, Puga FJ, Dearani JA, McGregor CG, Tazelaar HD, et al. Surgical resection of ventricular cardiac fibromas: early and late results. Ann Thorac Surg. 2003;76:1929-34.

\title{
Simultaneous repair for aortic incompetence with annuloaortic ectasia and pectus excavatum by modified Ravitch procedure with pectus bars in an adult patient with Marfan syndrome
}

\author{
Yang Gi Ryu, MD, Man-Jong Baek, MD, Hyun Koo Kim, MD, Young Ho Choi, MD, Young-Sang Sohn, MD, \\ and Hark Jei Kim, MD, Seoul, Republic of Korea
}

Concomitant thoracic reconstruction in patients with Marfan syndrome, pectus excavatum, and associated aortic or cardiac surgery poses a major clinical challenge.

\section{CLINICAL SUMMARY}

A 39-year-old man was seen with dyspnea in March 2008. He had no history of musculoskeletal disease or heart disease apart from Marfanoid features according to the Ghent criteria $^{1}$ seen on general examination: kyphoscoliosis, pectus excavatum, arachnodactyly, severe myopia, and diastolic murmur on the apex. Routine laboratory values were also unremarkable. Transthoracic and transesophageal echocardiography showed severely dilated ascending aorta, severe aortic regurgitation, moderate mitral and tricuspid regurgitation, and a small type II atrial septal defect. Computed tomographic scans showed a fusiform aneurysm of the proximal

From the Department of Thoracic and Cardiovascular Surgery, Guro Hospital, Korea University Medical Center, Seoul, Republic of Korea.

Received for publication July 18, 2008; accepted for publication July 26, 2008.

Address for reprints: Man-Jong Baek, MD, Department of Thoracic and Cardiovascular Surgery, Guro Hospital, Korea University Medical Center, Guro 2-Dong, Guro-

Gu, Seoul, Republic of Korea, 152-703 (E-mail: mdmjbaek@korea.ac.kr).

J Thorac Cardiovasc Surg 2009;137:e34-6

$0022-5223 / \$ 36.00$

Copyright (c) 2009 by The American Association for Thoracic Surgery doi:10.1016/j.jtcvs.2008.07.042 ascending aorta with a maximum diameter of $73 \mathrm{~mm}$, severe pectus excavatum (pectus index of 32.6; Figure 1), thoracolumbar scoliosis, and dural ectasia of the lumbosacral area.

Surgery was initiated with a chevron submammary skin incision. The pectoralis muscles were detached from the

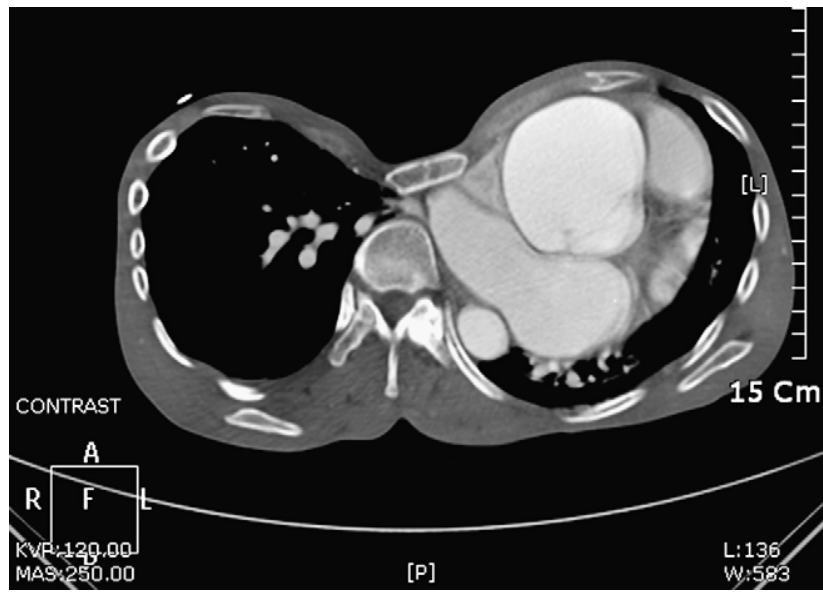

FIGURE 1. Preoperative computed tomography of pectus excavatum and annuloaortic ectasia. Axial computed tomographic scan at level of aortic root shows severe depression of sternum and marked dilatation of aortic root, with severe displacement of heart into left side of chest with compression of left lung. 

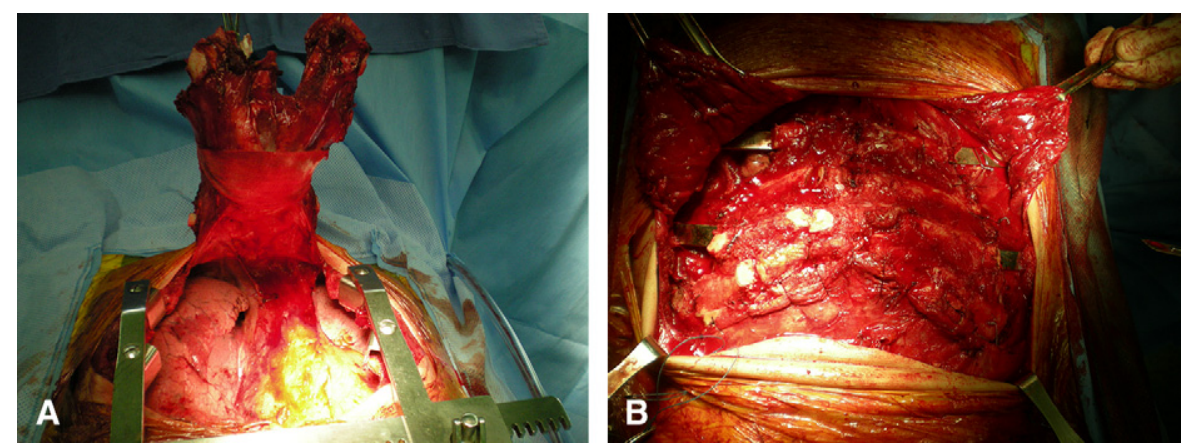

FIGURE 2. Intraoperative findings. A, Retraction of pedicled sternum in trapdoor fashion. B, Reconstruction of thorax with pectus bars.

sternum and retracted laterally, and the rectus abdominis muscles were mobilized inferiorly to expose the deformed costal cartilages. Segmental fractures from the second to seventh costal cartilage were performed at the costochondral junction. A transverse anterior osteotomy of the sternum was created over the level of the manubriosternal junction and fifth cartilage. Bilateral pleura below the costochondral junction were opened to obtain an optimal operative field of the heart, ascending aorta, and aortic arch. The sternum was dissected free from the intercostal neurovascular bundles bilaterally, medial to the internal thoracic arteries all the way up to the second costal cartilage level. This pedicled sternum was then wrapped with wet gauze and retracted cephalad in trapdoor fashion, resulting in perfect exposure of both the heart and the aortic root (Figure 2, A). Under cardiopulmonary bypass, the mitral valve was replaced with a mechanical valve, the aortic root was replaced with a $25-\mathrm{mm}$ valved conduit (St Jude Medical Inc, St Paul, Minn), tricuspid valvuloplasty was performed by the De Vega method, and the atrial septal defect was closed directly. After an uneventful weaning from cardiopulmonary bypass, the chest wall reconstruction was completed. Both $280-\mathrm{mm}$ and $320-\mathrm{mm}$ pectus bars (MX-bar system; Medix Align Technology, Seoul, Korea) were bent into a convex shape, conforming to the desired curvature of the thoracic cavity anteriorly. The bars were placed across the mediastinum under the pedicled sternum. Both ends and hinge points of the bars were firmly fixed to the ribs with pericostal steel wire sutures (Figure 2,B). The pectoralis and rectus muscles were reattached to the sternum after positioning of mediastinal and pleural drains. The patient was discharged after an uneventful recovery on postoperative day 35 with a regimen of warfarin sodium.

\section{DISCUSSION}

There is a definite association of cardiovascular anomalies with thoracic skeletal deformities in patients with Marfan syndrome. The main issue in such cases is how to approach and repair both the pectus excavatum and any cardiac disease in a single stage because of the difficulties that may result from the cardiac displacement into the left thoracic cavity. Some reports discourage simultaneous repair of both lesions because of concerns regarding the potential for major complications, such as limited exposure of the heart, excessive bleeding, and increased risk of wound infection. $^{2}$ Others, however, have reported successful single-stage corrections of both lesions without any complications. ${ }^{3,4}$ Historically, numerous modifications have been proposed for simultaneous repair of the pectus excavatum and cardiac disease, including sternal turnover or horizontal or vertical sternal splits. With regard to internal prosthetic sternal support, controversy remains among surgeons regarding its necessity and the propriety of its routine use, whether selectively or otherwise.

Notwithstanding, good sternal healing has been reported with temporary or permanent retrosternal bars, resulting in an essentially normal, cosmetically appealing restoration of the chest wall with no pectus recurrence. ${ }^{5}$ This approach, however, may present difficulties in approach for reoperation. Although recent clinical results have been favorable for the minimally invasive repair of pectus excavatum in some older patients, the Ravitch-type procedure is still superior to the minimally invasive method because of the more complex nature and greater severity of deformity in adult patients with Marfan syndrome. Furthermore, with respect to intracardiac exposure and postoperative sternal viability, retraction of the pedicled sternum in trap door fashion as described here could safely and effectively achieve excellent cardiac and aortic root exposure for complex procedures requiring long ischemic times, because both internal thoracic arteries are well preserved.

The described modifications of the Ravitch technique are intended to achieve simultaneous repair of both pectus excavatum and cardiac lesions. We hope that they may lead to development of ever safer and more effective strategies that will allow greater reduction in morbidity and mortality in this high-risk population.

\section{References}

1. De Paepe A, Devereux RB, Dietz HC, Hennekam RC, Pyeritz RE. Revised diagnostic criteria for the Marfan syndrome. Am J Med Genet. 1996;62:417-26. 
2. Shamberger RC, Welch KJ, Castaneda AR, Keane JF, Fyler DC. Anterior chest wall deformities and congenital heart disease. J Thorac Cardiovasc Surg. 1988; 96:427-32.

3. Pevni D, Lev-Ran O, Shapira I, Mohr R. Combined repair of pectus excavatum and coronary artery bypass grafting. Eur J Cardiothorac Surg. 2000;17:495-7.
4. Chien HF, Chu SH. Simultaneous Bentall's procedure and sternal turnover in a patient with Marfan syndrome. J Cardiovasc Surg (Torino). 1995;36:559-62.

5. Kim HK, Choi YH, Shim JH, Baek MJ, Sohn YS, Kim HJ. Modified Ravitch procedure: using a pectus bar for posttraumatic pectus excavatum. Ann Thorac Surg. $2007 ; 84: 647-8$

\section{Mitral valve repair during bypass in a 4-year-old girl with familial Evans syndrome}

Aitizaz Uddin Syed, FRCS Ed, FRCS (C), Ali E. Jelly, MD, Arto Nemlander, MD, and FathelRahman Elawad Ahmed, MD, Tabuk, Saudi Arabia

In patients with Evans syndrome, autoantibodies of the IgG type are produced against red cells, platelets, and granulocytes, leading to phagocytosis of the coated cells by the reticuloendothelial system. This leads to recurrent episodes of intravascular hemolysis and thrombocytopenia in the affected individuals. ${ }^{1}$ We report our experience of open mitral valve repair during cardiopulmonary bypass in a 4-year-old girl. This is the first reported case of a cardiac operation in a patient affected with this rare disorder.

\section{CLINICAL SUMMARY}

The patient presented in March 2004 with mild mitral regurgitation. She was known to have antibody-mediated hemolytic anemia and low platelets counts. This child came from a unique family in which 2 other siblings were given diagnoses of "Evans syndrome."

Her mitral valve regurgitation continued to worsen rapidly, leading to shortness of breath on mild exertion. Echocardiographic analysis in February 2005 showed severe mitral regurgitation with anterior mitral leaflet prolapse. Vena contracta was $6 \mathrm{~mm}$, with an effective regurgitant orifice of $40 \%$ and a mildly dilated left ventricle with good systolic function.

Open mitral valve repair was carried out on December 2, 2006. A cardiopulmonary bypass machine with roller pumps was used during the operation. Moderate hypothermia $\left(32^{\circ} \mathrm{C}\right)$, bicaval venous cannulation, and cold blood cardioplegic arrest were used. Usual heparinization (300 U/kg unfractionated heparin administered intravenously) with

From the North West Armed Forces Hospital, Tabuk, Saudi Arabia.

Received for publication March 22, 2008; revisions received May 6, 2008; accepted for publication June 15, 2008.

Address for reprints: Aitizaz Uddin Syed, FRCS Ed, FRCS (C), Consultant Cardiac Surgeon, North West Armed Forces Hospital, PO Box, 100, Tabuk, Saudi Arabia (E-mail: Aitizaz@hotmail.com).

J Thorac Cardiovasc Surg 2009;137:e36-7

$0022-5223 / \$ 36.00$

Copyright (c) 2009 by The American Association for Thoracic Surgery doi:10.1016/j.jtcvs.2008.06.033 periodic activated clotting time measurement during bypass and reversal with protamine at the end of the procedure was performed. A routine cardiotomy sucker with return of the collected blood to a venous reservoir was also used.

The mitral valve had a dilated annulus and prolapse of the anterior mitral leaflet at the A2 segment, with elongated chordae.

Chordal repositioning of the involved segment was carried out. The corresponding papillary muscle was split longitudinally, and the tip containing the elongated chordae was bent downward on itself. This accomplished shortening of the chordae to the A2 segment. The tip of the repositioned (bent downward) half of the papillary muscle was sutured to the other half of the papillary muscle with 5-0 Prolene sutures. Edge-to-edge modified leaflet placation with 5-0 Tycron sutures was done on both commissures. A 27-mm St Jude Medical Tailor ring annuloplasty was carried out. Intraoperative transesophageal echocardiographic analysis confirmed only trace mitral regurgitation at the posteromedial commissure.

On the fourth postoperative day, dark (brown)-colored urine was noticed, with a significant decrease in hemoglobin levels. Analysis of urine confirmed hemoglobinuria. Peripheral blood smear microscopy showed scant fragmented red cells. The reticulocyte counts and serum lactate dehydrogenase levels were increased. A trial of intravenous immunoglobulin and steroids did not completely resolve the hemolysis. ${ }^{1}$ The patient required blood transfusion twice per week. She was discharged home 3 weeks after the operation.

From a cardiovascular point of view, she did well. Repeat echocardiographic analysis confirmed mild mitral regurgitation, a small regurgitant jet at the posteromedial commissure, and good biventricular function. The regurgitant jet was considered not significant on echocardiographic analysis.

She was followed up by the pediatric hematology section of our hospital. The girl required frequent admissions in the following months during which she received blood 